\title{
EFFECT OF NIGELLA SATIVA ON SERUM TESTOSTERONE LEVELS IN LETROZOLE INDUCED POLYCYSTIC OVARIAN SYNDROME IN MICE
}

\author{
Noreen Anwar, Shabnam Hamid*, Amer Nadeem**, Ayesha Asad ${ }^{* * *}$, Naureen Waseem****, Nomana Mehmood***** \\ Quetta Institute of Medical Sciences, Quetta/National University of Medical Sciences (NUMS) Pakistan, *Army Medical College/National \\ University of Medical Sciences (NUMS) Rawalpindi Pakistan, ${ }^{* *}$ Combined Military Hospital, Quetta/ National University of Medical Sciences \\ (NUMS) Pakistan, ${ }^{* * *}$ Quetta Institute of Medical Sciences, Quetta National University of Medical Sciences (NUMS) Pakistan, ${ }^{* * * *}$ Islamic \\ Medical College, Sialkot Pakistan, ${ }^{* * * *}$ Wah Medical College, Wah National University of Medical Sciences (NUMS) Pakistan
}

\begin{abstract}
Objective: Monitor the ameliorative impact of Nigella sativa on fasting blood glucose and serum testosterone levels in polycystic ovarian syndrome caused by letrozole in mice.

Study Design: Laboratory based randomized control trial.

Place and Duration of Study: Anatomy department, Army Medical College in teamwork with National Institute of Health. Time span is Dec 2014 Dec 2015.

Methodology: Total 40 mature female BALB/c mice were chosen and distributed in four groups (ten mice in each one). Group 1 was given normal diet. Rests of three groups were treated with Letrozole at dose of $1 \mathrm{mg} / \mathrm{kg}$ body weight once daily for eight weeks. Group 3 was also given Nigella sativa seeds powder at dose of $10 \mathrm{~g} / \mathrm{kg}$ body weight once daily starting at 22 day and continued up to eight weeks. Group 4 was treated with Nigella sativa oil at a dose of $4 \mathrm{ml} / \mathrm{kg}$ body weight once daily starting at 22 day and continued up to eight weeks. At termination of trial, fasting blood glucose level (FBG) was recorded by taking blood sample by glucometer from mouse lateral tail vein after 12 hours fasting. Mice with blood glucose level 250-464 mg/dl were marked hyperglycemic. Final blood sample was taken through cardiac puncture for serum testosterone evaluation.

Results: Fasting blood glucose and Serum testosterone levels were raised in group 2 animals in comparison to group 1 while they were reduced remarkably in group 3 and 4 in comparison of group 2.

Conclusion: Nigella sativa seeds in both solid and liquid state leave an identical curative impact on fasting blood glucose and serum testosterone levels in polycystic ovarian syndrome in mice.
\end{abstract}

Keywords: Fasting blood glucose, Letrozole, Nigella sativa, Polycystic ovarian syndrome, Serum testosterone level.

\footnotetext{
This is an Open Access article distributed under the terms of the Creative Commons Attribution License (http://creativecommons.org/licenses/by/4.0), which permits unrestricted use, distribution, and reproduction in any medium, provided the original work is properly cited.
}

\section{INTRODUCTION}

Polycystic ovary syndrome (PCOS) is examined as a frequently occurring endocrinopathies amongst females in their child bearing period even in the absence of other endocrine disorders. This syndrome is marked by raised androgen levels. Symptoms mostly include hirsutism, acne, menstrual irregularities and anovulation eventually leading to infertility ${ }^{1}$. In current years, recent researches have proved that females having polycystic ovarian syndrome present with fertility problems as well as they evolve certain metabolic derangements including dyslipidemia and resistance to insulin hormone ${ }^{2}$.

Correspondence: Dr Noreen Anwar, Assistant Professor of Anatomy, QIMS Quetta Pakistan

Received: 31 Dec 2019; revised received: 20 Mar 2020; accepted: 27 Mar 2020
Letrozole is an effective, nonsteriodal, aromatase inhibitor, originally used for postmenopausal breast cancer therapy. Aromatase, a representative of cytochrome $p 450$ hemoprotein carring enzyme complex superfamily, is the catalyst that is accountable of transforming androgens to estrogens. Therefore Letrozole, by obstructing the enzyme, is responsible for preventing estrogen synthesis and more androgeic production that is in turn leads to development of polycystic ovarian syndrome ${ }^{3}$.

Herbal drugs have definitive role in treatment of PCOS. They shows gradual curative effect with minimal side effects ${ }^{4}$. Nigella sativa Linn, frequently appreciated as black seeds, historically used for treatment of several diseases. Researches on positive impacts of Nigella sativa 
upon human health have been recorded but no research work about its action on ovary and serum testosterone levels has been still done. Raised serum testosterone levels are found to be hallmark in polycystic ovarian syndrome. Nigella sativa can significantly decrease the raised blood glucose level in animals with experimentally induced diabetes mellitus ${ }^{5}$. Nigella sativa has a positive effect on lowering serum cholesterol levels as it decreases cholesterol synthesis by hepatocytes and also decreases its absorption from small intestine $^{6}$. Oil of Nigella sativa has also effect in lowering serum cholesterol levels. Hence due to its hypolipidemic activity, oil of Nigella sativa has a protective role in atherosclerosis7.

The rationale of this trial is to monitor ameliorative action of powder as well as oil of Nigella sativa seeds on hyperglycemia and hyperandrogenism that is hallmark in mouse model of PCOS.

\section{METHODOLOGY}

This laboratory based randomized control trial was carried out at Anatomy Department of Army Medical College Rawalpindi, in team work with National Institute of Health (NIH) Islamabad, from Dec 2014 to Dec 2015. Forty, mature, non pregnant females, BALB/c mice having age of 6-8 weeks and weight 35-40 gm, grouped by random number method, selected by non-probability convenient sampling technique served in this trial. Mice were retained in four groups in $\mathrm{NIH}$ animal house and nourished with its lab feed for eight week.

Animals of group 1 were considered as control and fed with plain water. Group 2 was treated Letrozole at dose of $1 \mathrm{mg} / \mathrm{kg}$ body weight once daily for two months ${ }^{9}$. Group 3 was provided with Letrozole for eight weeks at dose of $1 \mathrm{mg} / \mathrm{kg}$ body weight and Nigella sativa seeds powder at a dose of 10 grams/kilogram body weight once daily that starts at 22 day and remained up to eight weeks. Group 4 was dealt with Letrozole for eight weeks at dose of $1 \mathrm{mg} / \mathrm{kg}$ body weight and Nigella sativa oil at a dose of 4 milliliter/kilogram body weight once daily that also starts at 22 day and remained up to eight weeks. All mice were fed by oral gavage tube ${ }^{11}$.

Letrozole tablets (Femara) were bought from Novartis Chemicals Import and Export Corporation (product no SO 102). The seeds of herb were picked from National Agriculture Research Center, examined and recognized as Nigella Sativa by Dr. Zafar, Botanist working at Quaid-e-Azam University, Islamabad. They were driven in electrical grinder to make a powder for group 3 and its oil was squeezed out for group ${ }^{4}$.

Fasting blood glucose levels (FBG) were recorded in the morning by taking blood sample from mouse lateral tail vein with the help of a glucometer after 12 hours fasting of all of animals at the end of experiment ${ }^{12}$. Mice having blood glucose level $250-464 \mathrm{mg} / \mathrm{dl}$ were stated hyperglycemic ${ }^{13}$.

Final blood sample was taken from animals in group 1, 2, 3 and 4 through cardiac puncture for serum testosterone quantification ${ }^{14}$. Serum was frosted and kept at $-70 \mathrm{C}$ for subsequent hormone estimation after appropriate labeling. Serum testosterone (ST) was assessed and calculated by Immunoassay.

Data was evaluated through statistical package for social sciences version 22. Descriptive statistics was applied for interpretation of results. Quantitative parameters were elicited as mean \pm standard deviation. One way analysis of variance (ANOVA) followed by post Hoc Tuckey test was applied to find out remarkable difference. Results with $p<0.05$ were thought to be significant.

\section{RESULTS}

Forty mature non-pregnant female BALB/c mice, having age 6-8 weeks, and average weight of $42.3 \pm 2.28$ were accustomed in this trial. The mean \pm SD of FBG level of mice in group 1 at the end of trial was $195.4 \pm 38.8 \mathrm{mg} / \mathrm{dl}$. The mean \pm SD of ST concentration of animals at the completion of study was $0.52 \pm 0.16 \mathrm{nmole} / \mathrm{l}$. The mean \pm SD of FBG level of animals of group 2 at the end of trial was $308.6 \pm 27.0 \mathrm{mg} / \mathrm{dl}$. The $p$-value was $<0.001$ when compared with control group 1, 
which was statistically significant. The mean \pm SD of ST level of animals at the completion of trial was $1.33 \pm 0.2$ nmole. The $p$-value was $<0.001$ in comparison of control group 1 and found to be group 2, which was also statistically significant. But it was statistically insignificant in comparison of group 1 and 3. The mean \pm SD of ST levels of animals of group 4 at end of study were $0.28 \pm$

Table-I: Showing comparison of mean \pm SD of FBG and ST in control group 1 and experimental groups 2, 3 and 4.

\begin{tabular}{l|c|c|c|c|c}
\hline & $\begin{array}{c}\text { Group 1 } \\
\text { Mean } \pm \text { SD } \\
(\mathbf{n}=\mathbf{1 0})\end{array}$ & $\begin{array}{c}\text { Group 2 } \\
\text { Mean } \pm \text { SD } \\
(\mathbf{n}=\mathbf{1 0})\end{array}$ & $\begin{array}{c}\text { Group 3 } \\
\text { Mean } \pm \text { SD } \\
(\mathbf{n}=\mathbf{1 0})\end{array}$ & $\begin{array}{c}\text { Group 4 } \\
\text { Mean } \pm \text { SD } \\
(\mathbf{n}=\mathbf{1 0})\end{array}$ & $p$-value \\
\hline FBG $(\mathrm{mg} / \mathrm{dl})$ & $195.40 \pm 38.81$ & $308.6 \pm 27.0$ & $222.0 \pm 54.72$ & $237.8 \pm 63.50$ & $0.001^{*}$ \\
\hline ST $(\mathrm{nmole} / \mathrm{l})$ & $0.519 \pm 0.16$ & $1.33 \pm 0.27$ & $0.268 \pm 0.10$ & $0.284 \pm 0.09$ & $0.001^{*}$ \\
\hline
\end{tabular}

$p$-value $<0.05$ is statistically significant, $*=$ highly significant

Table-II: Intergroup jaxtaposition of $p$-value of FBG and ST between control group 1 and experimental groups 2,3 and 4 .

\begin{tabular}{l|l|l|l|l|l|c}
\hline $\begin{array}{l}\text { Group } \\
\text { Comparison }\end{array}$ & $\begin{array}{c}\text { Group } \\
\text { 1 vs 2 }\end{array}$ & $\begin{array}{c}\text { Group } \\
\text { 2 vs 3 }\end{array}$ & $\begin{array}{c}\text { Group } \\
\text { 1 vs 3 }\end{array}$ & $\begin{array}{c}\text { Group } \\
\text { 2 vs 4 }\end{array}$ & $\begin{array}{c}\text { Group } \\
\text { 1 vs 4 }\end{array}$ & $\begin{array}{c}\text { Group } \\
\text { 3 vs 4 }\end{array}$ \\
\hline FBG & $0.001^{*}$ & $0.002^{*}$ & 0.609 & $0.012^{*}$ & 0.218 & 0.88 \\
\hline ST & $0.001^{*}$ & $0.001^{*}$ & $0.014^{*}$ & $0.001^{*}$ & 0.023 & 0.99 \\
\hline
\end{tabular}

$p$-value $<0.05$ is statistically significant

statistically significant. The mean \pm SD of FBG levels of animals of group 3 at completion of experiment were $222.0 \pm 54.72 \mathrm{mg} / \mathrm{dl}$. The $p$-value was 0.02 when compared with control group 2, which was also statistically significant. But it was statistically insignificant when compared with group 1 . The mean \pm SD of ST levels of animals of group 3 at the end of study was $0.27 \pm 0.1$ nmole/1 and found to be statistically significant in comparison of group 1 and 2.

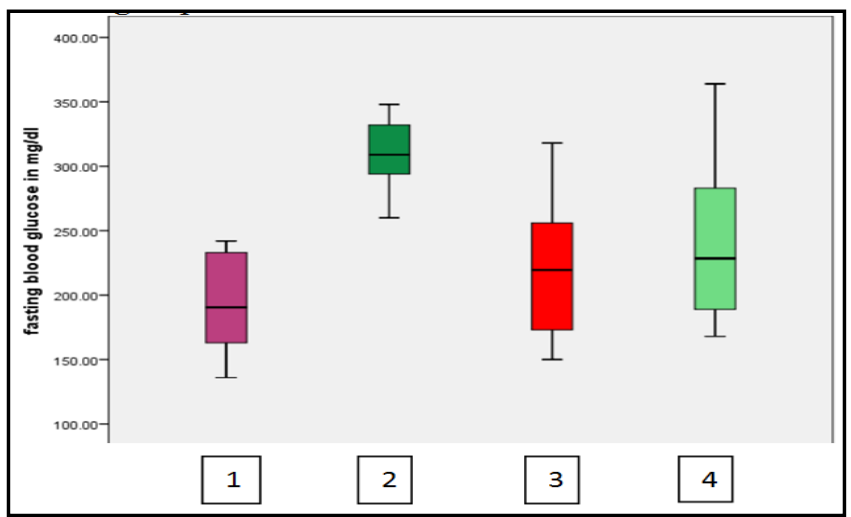

Figure-1: Box plot displaying comparison of mean values of fasting blood glucose between control group 1 and experimental groups 2, 3 and 4 .

The mean \pm SD of FBG levels of animals of group 4 at end of trial were $237.80 \pm 63.50 \mathrm{mg} / \mathrm{dl}$. The $p$-value was 0.012 when compared with
$0.98 \mathrm{nmole} / 1$. This was statistically significant when compared with group 1 and 2 but insignificant when compared with group 3 .

\section{DISCUSSION}

Polycystic ovarian syndrome is becoming a subject of high interest now days as it is influencing more than $10 \%$ females in their reproductive period and responsible for fertility problems in these women. Women with PCOS are mostly obese presenting commonly with hyperandroge-

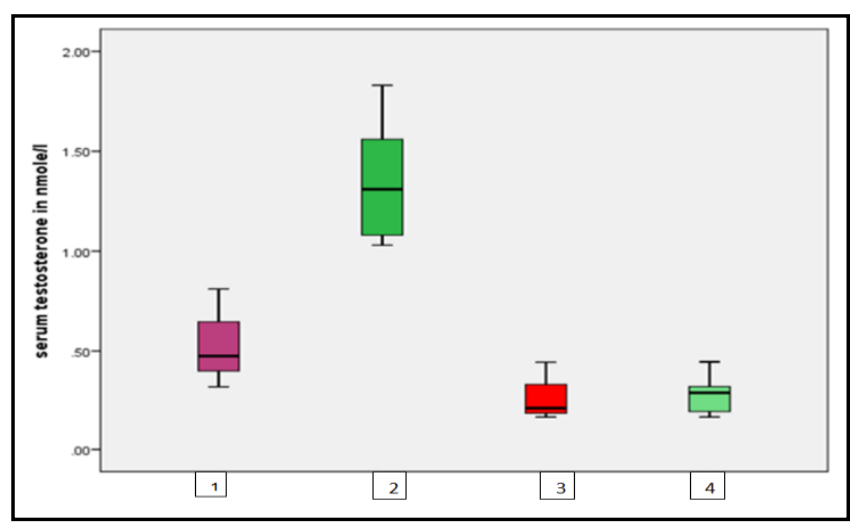

Figure-2: Box plot displaying comparison of mean values of ST among control group 1 and experimental groups 2, 3 and 4 .

nism and insulin resistance and they are most likely at risk of developing type 2 diabetes ${ }^{15}$. Insulin plays a significant role in pathogenesis of 
PCOS as these patients mostly develop resistance to insulin hormone and in turn concentration of hormone is increased for compensation. This insulin first increases unbound and active androgen level by ameliorating androgen production by theca cells and then it also arrests hepatic synthesis of sex hormone-binding globulin (SHBG) ${ }^{16}$. Then raised insulin concentration which occurs in compensation to insulin resistance is mostly responsible for increased androgen concentration ${ }^{17}$. The aim of this research is to monitor ameliorative impact of Nigella sativa in animals in which polycystic ovarian syndrome is induced experimentally by the drug Letrozole.

Fasting blood glucose levels in animals of group 2 were remarkably increased in comparison of group 1. This hyperglycemia in PCOS rats was due to insulin resistance. However, compensatory hyperinsulinemia developed in these rats along with increased truncal fats, with low estrogen and raised androgens ${ }^{18,19}$. FBG of animals of group 3 and 4 were significantly decreased when compared with group 2. This hypoglycemic impact of Nigella sativa seeds and its oil was due to its ability to improve insulin resistance and extrapancreatic action of insulin ${ }^{15}$. Another study carried out on patients diagnosed as cases of metabolic syndrome, reported that Nigella sativa decreases fasting blood glucose levels in these patients due to its insulin sensitizing action ${ }^{20}$.

Serum testosterone level was remarkably increased in group 2 as compared to group 1 . Letrozole, being an aromatase inhibitor, stops aromatization and the conversion of androgens to estrogens. Hence it is responsible for an increase of circulating and ovarian androgen levels ${ }^{8}$. Moreover, hyperandrogenism is closely related to ovulatory dysfunction and follicle excess along with formation of cystic follicles. Accordingly, hyperandrogenism also leads to resistance to Insulin hormone and raised insulin levels for compensation ${ }^{21}$. Nigella sativa, acting as hypoglycemic agent ameliorate this resistance to insulin as well as hyperinsulinemia ${ }^{20}$. Therefore, insulin sensitizing agents by lowering down serum insulin also decreases androgen levels ${ }^{22}$. Hence, serum androgen level is remarkably lowered down in animals of group 3 and 4 as compared to group 2. Therefore Nigella sativa ameliorates this insulin susceptibility and hyperinsulinemia in experimental animals in its both forms, and finally lowers the serum testosterone concentrations in animals of group 3 and 4.

\section{CONCLUSION}

Nigella sativa has an ameliorative impact on serum androgen levels in Letrozole induced PCOS by decreasing fasting blood glucose levels and improving insulin resistance in its liquid as well as in solid states.

\section{CONFLICT OF INTEREST}

The study has no conflict of interest declared by any of the author.

\section{REFERENCES}

1. Rajender S, Carlus SJ, Bansal SK, Negi MP, Sadasivam N, Sadasivam MN, et al. Androgen receptor CAG repeats length polymorphism and the risk of polycystic ovarian syndrome (PCOS). PloS One 2013; 8(10): e75709-12.

2. Sandhu H, Kuburas R. Insulin resistance in women with polycystic ovary syndrome: optimizing treatment by implementing an in vitro insulin resistance organ culture model. Clinics Mother Child Health 2015; 12(1): e107-10.

3. Misso ML, Wong JL, Teede HJ, Hart R, Rombauts L, Melder AM, et al. Aromatase inhibitors for PCOS: a systematic review and meta-analysis. Human Reproduction Update 2012; 18(3): 301-12.

4. Goswami PK, Khale A, Ogale S. Natural remedies for polycystic ovarian syndrome (PCOS): a review. Inter J Pharmaceut Phytopharmacol Res 2012; 1(6): 396-02.

5. Abbasi P, Tabassum S, Abbasi SK, Khan H. Blood glucose lowering effect of Nigella sativa in alloxan induced diabetic rats. Direct Res J Health Pharmacol 2014; 2(2): 10-13.

6. Farzaneh E, Nia FR, Mehrtash M, Mirmoeini FS, Jalilvand M. The effects of 8-week Nigella sativa supplementation and aerobic training on lipid profile and VO2 max in sedentary overweight females. Inter J Prevent Med 2014; 5(2): 210-12.

7. Dahri AH, Chandio AM, Rahoo AA, Memon RA. Effect of Nigella sativa (kalonji) on serum cholesterol of albino rats. J Ayub Med College Abbottabad 2005; 17(2): 72-74.

8. Kafali H, Iriadam M, Ozardal I,Demir N. Letrozole-Induced Polycystic Ovaries in the Rat: A New Model for Cystic Ovarian Disease. Med Res 2004; 35(2): 103-08.

9. Sun J, Jin C, Wu H, Zhao J, Cui Y, Liu H, et al. Effects of ElectroAcupuncture on Ovarian P450arom, P450c17a and mRNA Expression Induced by Letrozole in PCOS Rats. PLoS One 2013; 8(11): e79382-85.

10. Mathur M, Gaura J, Sharmaa R, Haldiyaa K. Antidiabetic Properties of a Spice Plant Nigella sativa. Endocrinol and Metab 2013; 1(1): 1-8.

11. Danladi J, Abdulsalam A, Timbuak A, Ahmed S. Dahiru A. Hepatoprotective Effect of Black Seed (Nigella sativa) oil on Carbon Tetrachloride (CCl4) Induced Liver Toxicity in Adult Wistar Rats. IOSR J Dental Med Scie 2013; 4(3): 56-62. 
12. Wang $Y$, Xiang L, Wang C, Tang C, He X. Antidiabetic and antioxidant effects and phytochemicals of mulberry fruit (Morus alba L.) polyphenol enhanced extract. PLoS One 2013; 8(7): e71144-48.

13. Tsuneki H, Sugihara $Y$, Honda R, Wada T, Sasaoka T, Kimura I. Reduction of blood glucose level by orexins in fasting normal and streptozotocin-diabetic mice. Europ J Pharmacol 2002; 448(2-3): 245-52.

14. Wisniewski P, Romano RM, Kizys MM, Oliveira KC, Kasamatsu T, Giannocco G, et al. Adult exposure to bisphenol A (BPA) in Wistar rats reduces sperm quality with disruption of the hypothalamic-pituitary-testicular axis. Toxicol 2015; 329(1): 1-9.

15. Van Houten EL, Visser J. Mouse models to study polycystic ovary syndrome: A possible link between metabolism and ovarian function. Reprod Biol 2014; 14(1): 32-43.

16. Genazzani AD, Prati A, Despini G, Marini G, Ricchieri F. PCOS from Lifestyle to the Use of Inositol and Insulin Sensitizers. In Front Gynecol Endocrinol 2014: pp.59-67.

17. Rosenfield RL. The pathogenesis of polycystic ovary syndrome (PCOS): the hypothesis of PCOS as functional ovarian hyperandrogenism revisited. Endocrine Rev 2016; 37(5): 467-20.
18. Radha M, Padamnabhi N, Laxmipriya N. Evaluation of Aloe barbadensis mill. Gel on letrozole induced polycystic ovarian syndrome (pcos) rat model-a dose dependent study. Inter J Pharmaceut Sci Res 2014; 5(12): 5293-95.

19. Maliqueo M, Sun M, Johansson J, Benrick A, Labrie F, Svensson $\mathrm{H}$, et al. Continuous administration of a P450 aromatase inhibitor induces polycystic ovary syndrome with a metabolic and endocrine phenotype in female rats at adult age. Endocrinol 2013; 154(1): 434-45.

20. Ibrahim RM, Hamdan NS, Ismail M, Saini SM. Protective effects of Nigella sativa on metabolic syndrome in menopausal women. Advanced Pharmaceut Bullet 2014; 4(1): 29-31.

21. Jonard S, Dewailly D. The follicular excess in polycystic ovaries, due to intraovarian hyperandrogenism, may be the main culprit for the follicular arrest. Hum Reprod Update 2004; 10(2): 107-17.

22. Shah AS, Khan GM, Badshah A, Shah SU, Shah KU, Mirza SA, et al. Nigella sativa provides protection against metabolic syndrome. African J Biotechnol 2012; 11(48): 10919-25.

23. Jakubowicz D, Barnea M. Effects of caloric intake timing on insulin resistance and hyperandrogenism in lean women with polycystic ovary syndrome. Clinical Sci 2013; 125(9): 423-32. 